\title{
A rare case of angina in a patient with coronary artery microfistulas - role of echocardiographic examination
}

\author{
Hrvoje Jurin ${ }^{1 *}$, Nikša Drinković Jr. ${ }^{1}$, Kristina Marić', Vlatka Rešković Lukšić1, Nikša Drinković Sr. ${ }^{2}$ \\ ${ }^{1}$ University of Zagreb School of Medicine, University Hospital Center Zagreb, Zagreb, Croatia \\ 2Polyclinic Nikša Drinković, Zagreb, Croatia
}

The goal: To point out the role of echocardiographic examination in diagnosing coronary microfistulas.

Case presentation: The patient (male; 58) with so far unremarkable medical history presented to our department due to newly developed exertional chest pain and concordant abnormal ECG findings - negative T waves with ST segment depression $<1 \mathrm{~mm}$ in lateroapical chest leads. Following the complete clinical examination which showed normal findings, the patient was sent to perform the cardiac stress test which showed no changes in relation to the ones observed in resting. Afterwards the patient was instructed to perform thallium-201 stress myocardial perfusion test. The latter indicated the presence of reversible hypoperfusion area in anteroapical segment of left heart myocardium. Therefore, the patient was scheduled for elective coronary angiography. Before the invasive diagnostics were undertaken, an echocardiography was done on which a characteristic cluster of intramyocardial high velocity "color spots" were appreciated in standard color Doppler gain and depth settings within the anteroapicolateral region of the left ven- tricle (Figure 1). Coronary blood flow was easily demonstrated in these malformations using pulsed wave Doppler (Figure 2) and normal left ventricle wall thickness was observed. All the other echocardiography findings were described as normal. Afterwards, coronary angiography was undertaken. Initial injections into left coronary artery revealed characteristic direct diffuse shunting of contrast from diagonal branch and distal left anterior descending artery into the left ventricle cavity through multiple microfistulas (Figure 3). The right coronary artery was not affected by the phenomenon. Also the cardiovascular magnetic resonance imaging was done which depicted multiple punctiform hyperintensities on cine sequences within the anterior and anterolateral region of the left ventricle. The patient was discharged from the hospital and treated symptomatically by vasodilators. He was reviewed through to 1 year period after the index hospitalization and remained well.

Conclusion: Coronary artery microfistulas are rarely seen as malformations which are usually asymptomatic, but can also cause a diverse variety of clinical symptoms. The true

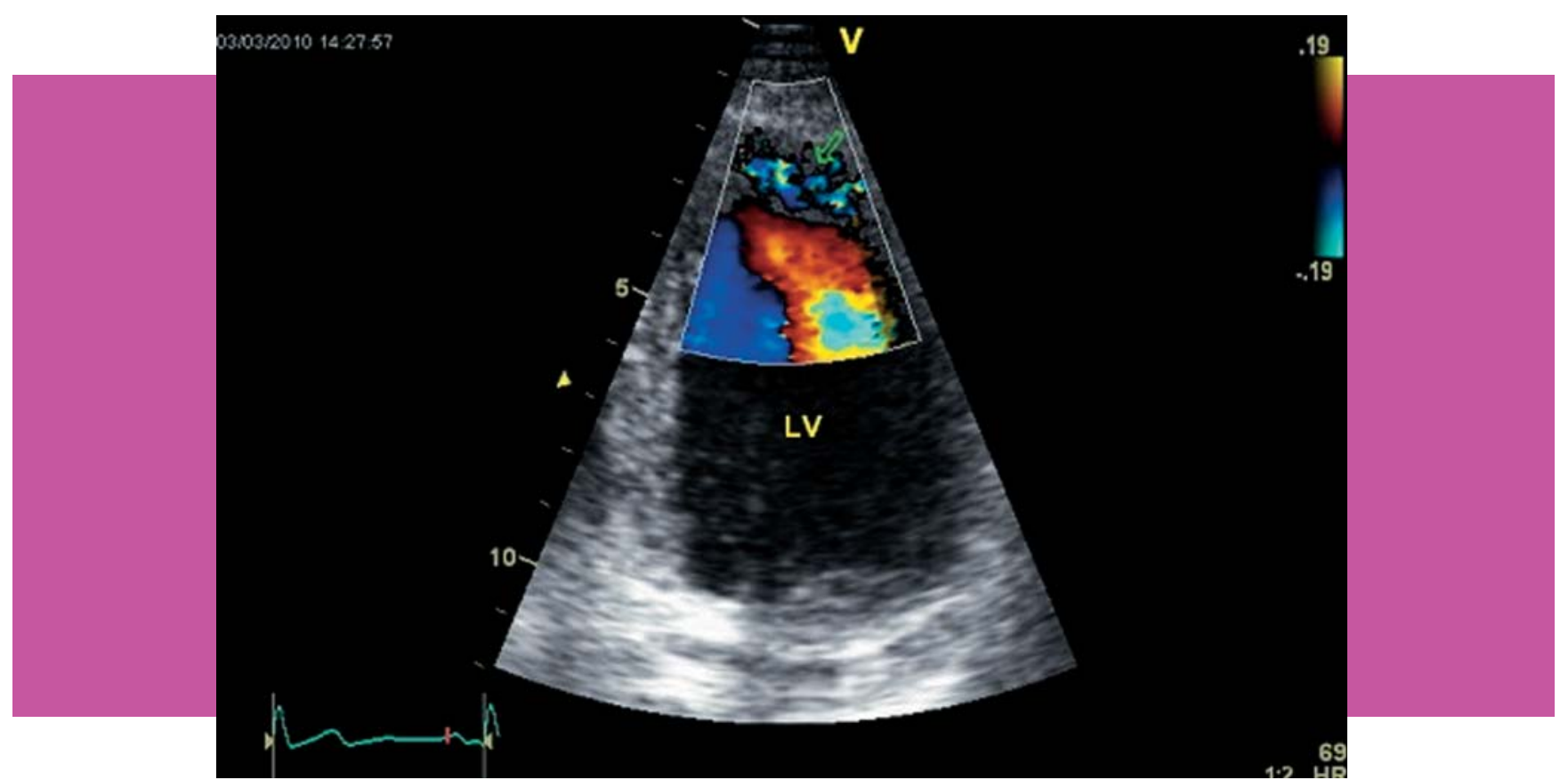

Figure 1. Standard Color Doppler gain and depth settings showing coronary microfistulas as characteristic cluster of intramyocardial high velocity "color spots". 


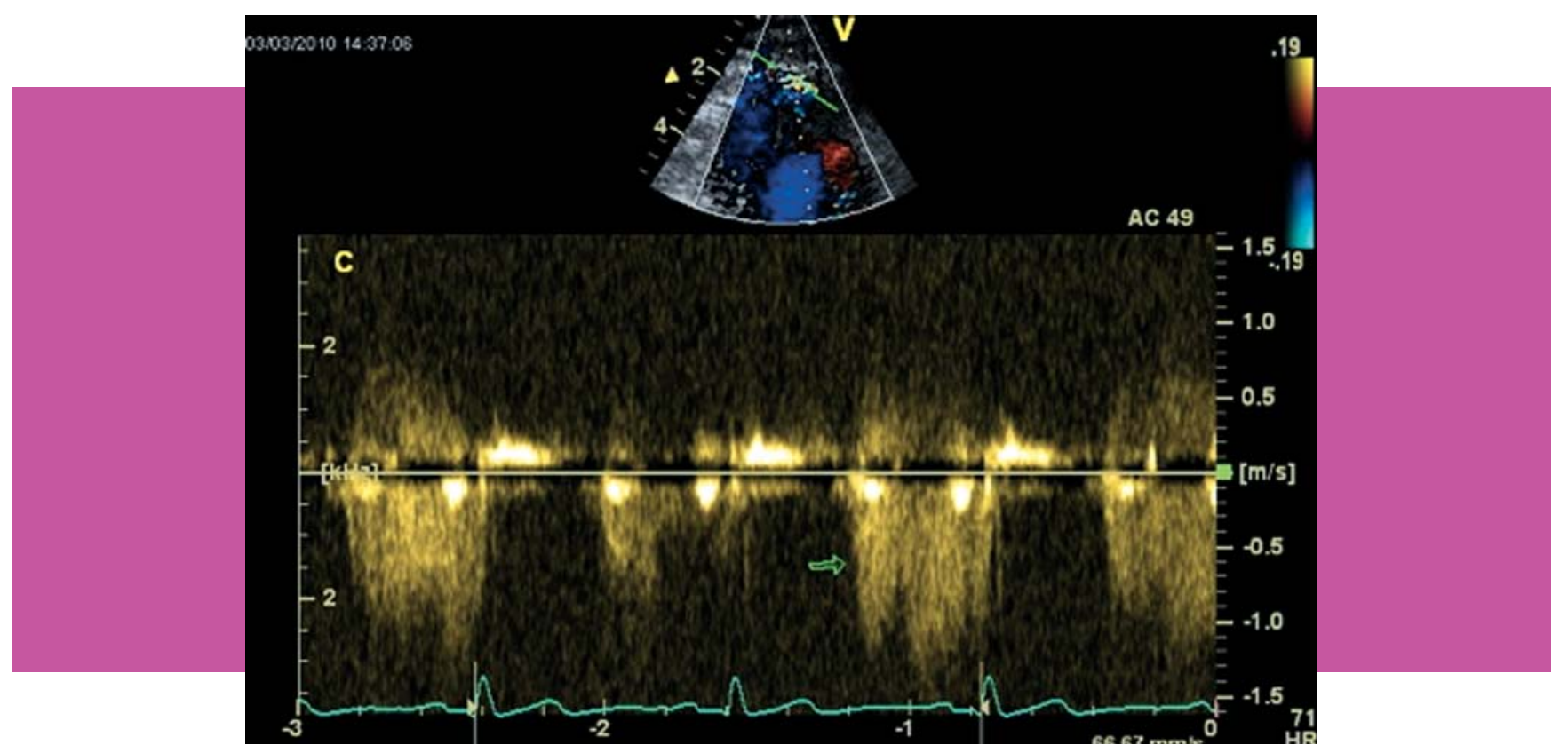

Figure 2. Power Doppler zoom mode showing coronary blood flow within microfistulas.

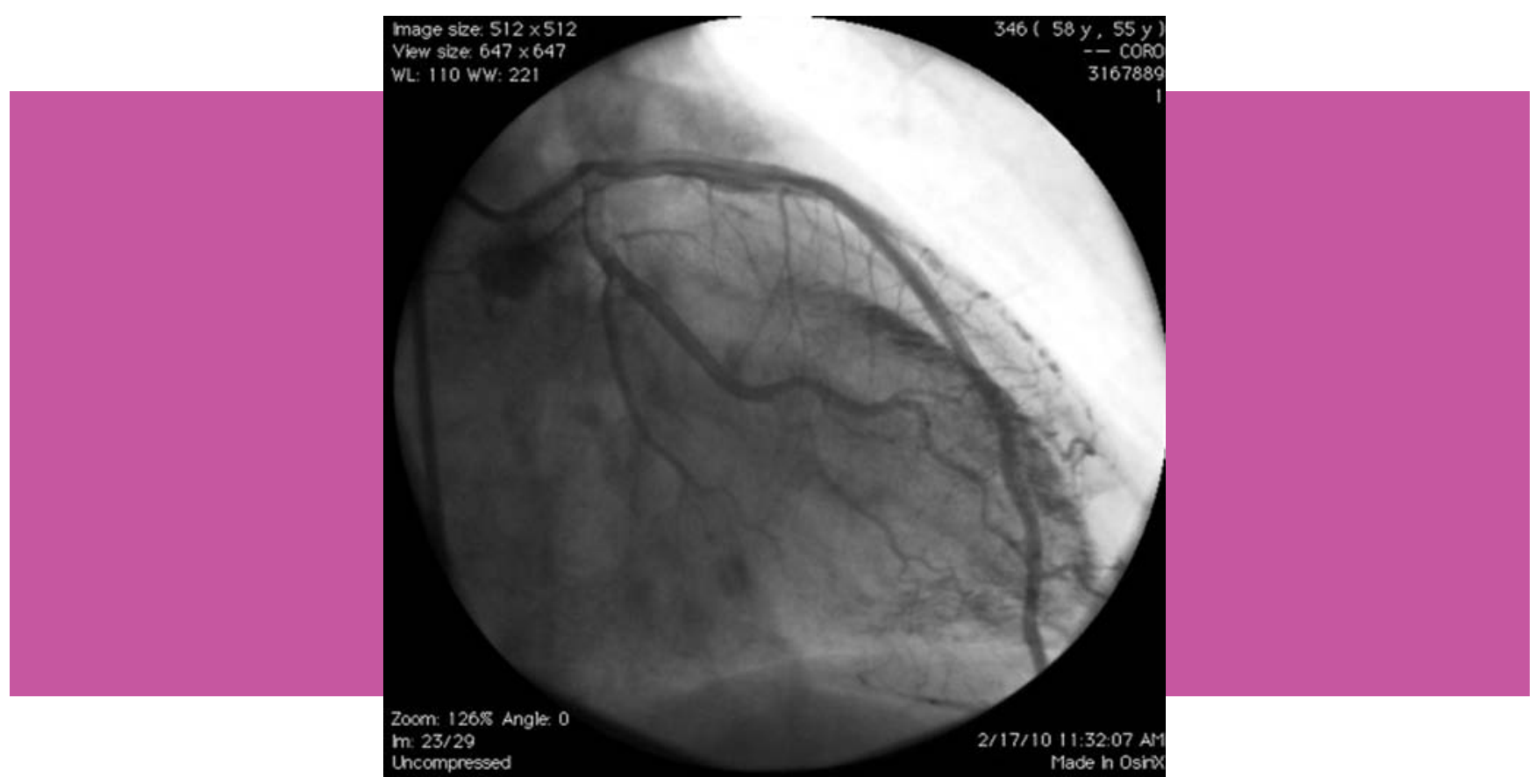

Figure 3. Coronary angiogram depicting direct shunting of contrast from diagonal branch and distal $L A D$ into the left ventricle cavity.

prevalence of these anomalies is yet to be determined. Coronary angiography remains to be the cornerstone in

Received: $20^{\text {th }}$ Apr 2014

*Address for correspondence: Klinički bolnički centar Zagreb, Kišpatićeva 12, HR10000 Zagreb, Croatia.

Phone: +385-98-525-002

E-mail: hrvoje.jurin@gmail.com determining the definite diagnose. Nevertheless, as we demonstrated in our patient, an echocardiographic examination can be used to indicate the presence of this kind of malformation.

KEYWORDS: coronary microfistulas, angina pectoris, echocardiography.

CITATION: Cardiol Croat. 2014;9(5-6):201-202.

\section{Literature}

1. Macfadyen RJ, Varma C, Anderson RH. Multiple microvessels extending from the coronary arteries to the left ventricle in a middle aged female presenting with ischaemic chest pain: a case report. J Med Case Rep. 2007;1:177.

2. Gowda RM, Vasavada BC, Khan IA. Coronary artery fistulas: clinical and therapeutic considerations. Int J Cardiol. 2006:107(1):7-10.

3. Canga Y, Ozcan KS, Emre A, et al. Coronary artery fistula: review of 54 cases from single center experience. Cardiol J. 2012;19(3):278-86. 